serum potassium was $4.45 \mathrm{mEq} /$ litre, and this rose steadily thereafter to $5.1 \mathrm{mEq} /$ litre one week later. His urinary potassium excretion likewise fell to $25 \mathrm{mEq} / 24$ hours with restoration of the $\mathrm{pH}$ to normal.

The possibility of a primary hyperaldosteronism (Conn's syndrome) was considered, but the fall in the urinary potassium output with the progressive rise in serum potassium in the presence of adequate sodium repletion tended to be against this; also the fact that the specific gravity of his urine, while originally 1010 , rose after repletion to 1015 and 1020. Familial periodic paralysis was likewise considered, but did not seem likely from the history. The low calcium levels may be associated with increased calcium excretion, which, while not estimated in this case, has been reported to occur in patients on carbenoxolone therapy and may be influenced by the accompanying sodium retention.

It is felt that this case is of interest in two ways: (a) The fact that a dangerous degree of hypokalaemia occurred in a patient taking this drug for a period within the prescribed time and not in excessive dosage and not in association with diuretics; and (b) that the hypokalaemia induced was initially refractory to replacement therapy even in large amounts. Whether or not this was due to carbenoxolone lying in quantities in an atonic bowel is open to conjecture. Although the other possible diagnoses have been mentioned and perhaps may still have to be borne in mind, it would seem most likely that this man's hypokalaemia was Duogastrone-induced, since he is now well and maintains his serum potassium within normal levels.-We are, etc.,

\section{A. MUIR.}

J. A. Laithwaite.

Law Hospital, W. WOOD.

Carluke, Lanarks.

\section{Dangers of Perchlorethylene}

SIR,-There has been recent public interest ${ }^{1}$ in the possible dangers associated with the use of perchlorethylene in coin-operated dry cleaning machines. It was therefore felt appropriate to report the following case.

A 68-year-old man worked a few hours a day maintaining a launderette. On 5 January 1969 a container of perchlorethylene spilt ove him, soaking his clothes. He was anaesthetized by the material, and lay unconscious for half an hour before being found. He was resuscitated in the casualty department of the local hospital. He was noted to have erythema and blistering amounting to $30 \%$ of his surface area involving his neck, shoulders, left side of his chest and abdomen, left thigh, and perineum. As these were in the nature of chemical burns he was transferred to the burns centre. His appearance on admission was of a $30 \%$ superficial burn, and he was therefore treated with intravenous plasma, and antibiotics were commenced. The areas were exposed; the blisters were not deroofed, as they were very small. Five days later the erythema had subsided considerably and the blistering had gone; there was no cracking of the skin.

The patient was discharged and has been followed up by his general practitioner, $\mathrm{Dr}$. G. R. C. Fisher, who reports that his burns have healed very well, apart from some dryness and irritation. There is slight staining of the skin on the areas injured.
This case illustrates the two effects of perchlorethylene, which has anaesthetic properties and on prolonged contact can produce " defatting" of the skin. The damaged skin is likely to crack and thereby become infected. Perchlorethylene, however, is far less dangerous than carbon tetrachloride.I am, etc., \section{Mount Vernon Centre for
Plastic Surgery, \\ Mount Vernon Hospital,
Northwood, Middx. \\ REFERENCB \\ 1 The Guardian, 28 March 1969.}

Brian Morgan.

\section{Lymphoblastic Leukaemia}

SIR,-The interesting paper by Dr. H. C. Laurie $^{1}$ demonstrating that strong periodicacid-Schiff (P.A.S.) reactivity in the primitive cells of lymphoblastic leukaemia is inversely related to the progression of the disease has prompted us to review our experience with a large series of patients diagnosed and treated at the Clinical Center, National Cancer Institute, National Institutes of Health.

Bone marrow "squash" smears from 44 patients with acute lymphocytic leukacmia were evaluated prior to initial therapy. The mean age was 6 years. The term acute lymphocytic leukaemia encompassed all leukaemic "blasts" that showed any degree of lymphoid differentiation, and undoubtedly included many cases that are referred to as " acute stem cell" leukaemia by others. ${ }^{2}$ A P.A.S. scoring system similar to that proposed by Quaglino and Hayhoe ${ }^{3}$ was used. The leukaemic blast cells were graded from 0 to $3+$, and arbitrarily scores above 100 were considered elevated. In those cases with elevated scores ( $61 \%$ of group, or 27 patients) 2 and $3+$ reactive cells constituted 57 to $96 \%$ of the P.A.S.-positive cells. In the group with scores between 50 and 100 (four cases) $23 \%$ of the positive cells were 2 and $3+$, and in the lowest group (13 cases) $7 \%$ of the cells were $2+$ or $3+$.

Laurie reported that his patients could be readily divided into a group with less than $40 \%$ P.A.S.-negative blast cells and a group with greater than $55 \%$ P.A.S.-negative blast cells. The median survival in the former group was 25 months but only $11 \frac{1}{2}$ months in the latter. Analysing our data, a natural division was found with greater or less than $50 \%$ P.A.S.-negative blast cells. The median survival of both groups, 16 and 18 cases respectively, using life table methods, was $37 \cdot 5$ months for the weak P.A.S.-positive group and 33 months for the strong P.A.S.positive group; not statistically significant. Another minor subdivision was created with a group having $75 \%$ or more P.A.S.-negative blasts (nine cases) and the other group 25\% or less P.A.S.-negative blasts, 34 cases. The median survival of both groups was identical, namely $\mathbf{3 6}$ months. In all of the four groups there were at least two or more patients living and well a minimum of $3 \frac{1}{2}$ years from initiation of therapy.

Therefore, although our studies confirm the presence of significant amounts of P.A.S. positive material in the cytoplasm of leukaemic lymphoblasts from the majority of patients with acute lymphocytic leukaemia, the data do not support the usefulness of the P.A.S. reaction in predicting individual patient remission or survival.
These two studies also differ in their chemotherapeutic programmes. The patients studied by Laurie were treated initially with prednisone and 6-mercaptopurine or vincristine. ${ }^{4}$ Then, after remission induction, cyclical therapy with 6-mercaptopurine, methotrexate, and cyclophosphamide was administered sequentially. Some of our patients were initially treated with a combination of four drugs (vincristine, prednisone, methotrexate, and 6-mercaptopurine), or "VAMP." Twenty-four received an intensification of this programme, including monthly "pulses" for one year. ${ }^{s}$ It might be appropriate to point out that neither initial duration of symptoms nor leucocyte counts correlated with the duration of the first remission. Though the remission duration periods are approximately the same for both groups (6065 weeks), there is a longer survival in our series. Whether this is due to a greater reduction in leukaemic cells or a change in the kinetic behaviour of the cells is unclear. This additional period of prolongation of life in these children, however, may offset and conceal any difference that may have been detected by the P.A.S. method.-We are, etc.,

\section{JOHN M. BENNETT.}

\section{Tufts Hematology Laboratory,}

Boston, Mass., U.S.A.

EDWARD S. HENDERSON.

National Cancer Institute, National Institutes of Health.
Bethesda, U.S.A.

\section{REFERENCES} Laurie, H. C., British Medical fournal, 1968, 2,
95.

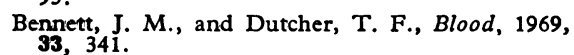
Quaglino, D., and Hayhoe, F. G. J., Journal of Willoughby, M. L. N., and Laurie, H. C., Archives of Disease in Childhood, 1968, 43, 187.

5 Henderson, E. S., Cancer Research, 1967, 27, 2570 .

\section{Management of Acute Salicylate Poisoning}

SIR,-We were very interested to read the valuable contribution by Drs. A. G. Morgan and A. Polak (4 January, p. 16), and the ensuing correspondence (18 January, p. 185 ; 1 February, p. 315 ; 8 February, p. 383 ; and 17 March, p. 577). As we have several years' experience of the treatment of salicylate poisoning, including the use of acetazolamide, we should like to make certain comments.

It is generally agreed that the renal excretion of salicylate depends partly on urine flow rate and partly on the alkalinity of the urine, but the relative importance of the two factors does not appear to have been worked out. We have therefore analysed our own records and also those which Dr. Morgan has kindly supplied to us and have calculated the crude clearance of salicylate (deriving free salicylate levels in plasma from total salicylate levels using the data of Moran and Walker). ${ }^{1}$ We then attempted to determine the separate effects of flow rate and alkalinity on the clearance.

The results are summarized in the Table and indicate that, to get the best clearance, (1) if relying mainly on alkalinity the urine flow should be at least $3 \mathrm{ml} . / \mathrm{min}$. and, except at high flow rates, the urine $p H$ should be greater than 7.5 ; (2) if relying mainly on 